\title{
La Resolución 4.327/2014, del Banco Central de Brasil, en el escenario de las cooperativas financieras brasileñas
}

\author{
José Eduardo de Miranda \\ Doctor en Derecho \\ Victória Corrêa Lima de Miranda \\ Estudiante de Derecho
}

En la cooperativa todos somos responsables por todo.

(Arizmendiarrieta, 1983, 61)

Sumario: Introducción; I. El sistema financiero brasileño y la misión del Banco Central de Brasil; II. Las cooperativas financieras en el contexto del sistema financiero brasileño; III. El objetivo de la Resolución 4.327/2014, del Banco Central de Brasil, y el sentido de la Política de Responsabilidad Socio Ambiental; IV. La Resolución 4.327/2014 en el escenario de las cooperativas financieras; $V$. La tenacidad de los principios cooperativos de la educación e información y de la preocupación por la comunidad en el proceso de ejecución de la Resolución 4.327/2014; VI. A título de conclusión: las políticas de responsabilidad social y ambiental son una tarea de casa de las cooperativas financieras; VII. Referencias.

Resumen: El sistema financiero brasileño fue instituido por la Ley 4.595, del 31 de diciembre de 1964. En el núcleo de su estructura normativa, el Banco Central de Brasil compone el subsistema normativo. Para mantener la conexión de las instituciones financieras con el compromiso del desarrollo sostenible, el Banco Central de Brasil editó la Resolución 4.327/2014, determinando que la obligación de las instituciones financieras implementar políticas de responsabilidad socio ambiental. En este contexto, las cooperativas financieras, sumisas a las reglas del sistema financiero brasileño, tienen en los valores y principios cooperativos una herramienta adecuada a la promoción de la responsabilidad socio ambiental.

Palabras clave: Cooperativas financieras. Banco Central de Brasil. Resolución 4.327/2014. 


\begin{abstract}
The Brazilian financial system was instituted by Law 4.595, of December 31, 1964. At the core of its regulatory structure, the Central Bank of Brazil composes the normative subsystem. In order to maintain the connection of financial institutions with the commitment of sustainable development, the Central Bank of Brazil issued Resolution 4.327/2014, determining that the obligation of financial institutions to implement socio-environmental responsibility policies. In this context, financial cooperatives, submissive to the rules of the Brazilian financial system, have an adequate tool in the values and cooperative principles to promote socio-environmental responsibility.
\end{abstract}

Keywords: Financial cooperatives. Central Bank of Brazil. Resolution 4.327/2014. 


\section{Introducción}

El sistema financiero brasileño surgió con la edición de la Ley 4.595, del 31 de diciembre de 1964, publicada para reglamentar la política, las instituciones monetarias, bancarias, de crédito, y crear el Consejo Monetario brasileño.

Dentro de esta perspectiva, la Constitución brasileña de 1988 establece, por el artículo 192, que el sistema financiero de Brasil es estructurado con el designio de viabilizar el desarrollo equilibrado del país, sirviendo a los intereses de la colectividad, en todas las partes que la componen, alcanzando a las cooperativas financieras.

Teniendo en cuenta la necesidad de adherir a las pautas internacionales inherentes al desarrollo sostenible, el sistema financiero de Brasil, a través del Banco Central, editó la Resolución 4.327/2014, instituyendo el carácter obligacional de implementación de políticas de responsabilidad socio ambiental por las instituciones financieras.

Por este camino, la resolución editada por el Banco Central brasileño determina que dichas políticas de responsabilidad socio ambiental necesitan atender a las directrices de los a los principios de la relevancia y de la proporcionalidad.

En este sentido, y una vez integrante del marco financiero brasileño, las cooperativas financieras tuvieran que ajustar sus estatutos sociales, dimensionando, o redimensionando, las normas destinadas a las prácticas sostenibles. Más allá de mencionar su elenco de principios, y manifestar la existencia de los valores del Cooperativismo, los estatutos sociales de las cooperativas financieras tuvieron que adecuarse a las exigencias de la Resolución 4.327/2014.

Por ello, comprendiese importante un análisis de la referida Resolución 4.327/2014, del Banco Central de Brasil, desde la óptica del Cooperativismo, especialmente el Cooperativismo financiero. Es importante observarse que el objetivo de la Resolución 4.327/2014 confluye a la finalidad del propio Cooperativismo, que es, arriba del todo, viabilizar la realización plena del hombre, permitiéndole encontrar las mejores condiciones de existencia digna.

Más allá de la prestación de unos servicios específicos a los cooperados y a sus clientes, las cooperativas financieras no pueden perder de su blanco la responsabilidad con la condición humana. Toda norma de regulación, fiscalización y control no puede quitárselas de un camino histórico que preserva todas las clases de cooperativas conectadas con unos valores y principios propios de quienes se han preocupado por el bien común de las gentes. "Aunque valiéndose de métodos que les son peculiares, las sociedades cooperativas 
todavía representan una mecánica de esfuerzo para defensa, realce y emancipación del Hombre». ${ }^{1}$

Defender, realzar y promover la emancipación del hombre, no es permitirle solamente la independización económicamente, sino que dárselo los medios adecuados para que reconozca que sus comunes y el medio ambiente natural son indispensables para su propio perfeccionamiento material, espiritual y moral. Hay que llevarse en cuenta, así, que los principios de la educación e información y de la preocupación por la comunidad representan una herramienta que anticipa la acción cooperativa en el desarrollo de prácticas y actitudes de responsabilidad social y ambiental.

De este modo, el presente trabajo hará un análisis de las principales características del Sistema Financiero brasileño, presentando-se las peculiaridades de la Resolución 4.327/2014, del Banco Central de Brasil. Asimismo, se presentará la vinculación de las cooperativas financieras al sistema financiero de Brasil, para, después, revelarse que en materia cooperativa, la preocupación socio ambiental antecede la acción económica y la disposición normativa. También, se quiere mostrar que los principios cooperativos de la educación y de la preocupación por la comunidad son indispensables para que las políticas de responsabilidad socio ambiental dejen de ser únicamente una pauta documental derivada del cumplimento de una regla reguladora, teniendo en cuenta que significan básicamente un deber que las cooperativas necesitan cumplir sistemáticamente.

\section{El sistema financiero brasileño y la misión del Banco Central de Brasil}

En Brasil, el sistema financiero fue instituido por la Ley 4.595, del 31 de diciembre de 1964, bajo un aspecto de representar el conjunto de normas jurídicas destinadas al reglamento del ejercicio de toda institución que actúa en el mercado financiero, para optimizar la transferencia de recursos económicos superavitarios a los deficitarios. ${ }^{2}$

De acuerdo con Fortuna, el sistema financiero es «um conjunto de instituições que se dedicam, de alguma forma, ao trabalho de propiciar

1 Miranda, José Eduardo de: De la crisis de identidad al rescate de la génesis del cooperativismo, Dykinson, Madrid, 2012, p. 15.

2 Assaf Neto, A.: Mercado financeiro, 4. ${ }^{a}$ ed, Atlas, São Paulo, 2001, 67. 
condições satisfatórias para a manutenção de um fluxo de recursos entre poupadores e investidores» ${ }^{3}$.

Bajo este aspecto, el artículo 192, de la Constitución Federal brasileña, establece que "o sistema financeiro nacional, estruturado de forma a promover o desenvolvimento equilibrado do País e a servir aos interesses da coletividade, em todas as partes que o compõem, abrangendo as cooperativas de crédito, será regulado por leis complementares que disporão, inclusive, sobre a participação do capital estrangeiro nas instituições que o integram.» 4

A par de ello, se puede decir que más allá de instituir el sistema financiero, la Constitución brasileña se encarga de constitucionalizar algunos de sus principios, definiendo que toda su estructura debe pautarse en la promoción del desarrollo equilibrado, y sirviendo a los intereses de la sociedad.

Con el propósito de atender el objetivo de su creación, el sistema financiero brasileño es compuesto por el Consejo Monetario brasileño, por el Banco Central de Brasil, por el Banco de Brasil S/S, por el Banco brasileño de Desarrollo Económico y por todas las demás instituciones públicas y privadas.

Independientemente de la naturaleza de las instituciones que forman el sistema financiero brasileño, el artículo 192 de la Constitución brasileña deja en evidencia que todas ellas, sean públicas o privadas, están sujetas al cumplimiento de funciones sociales bien caracterizadas.

Por ello, y cuando refierese al artículo 192 de la Constitución Federal de Brasil, Silva es categórico en el sentido de que el «dispositivo trata das relações institucionais do sistema financeiro, ou seja, aqui o que se busca regular são as relações do Poder Público com as instituições financeira públicas ou privadas».$^{5}$

Vista esta funcionalidad, hay que destacarse la importancia del Banco Central de Brasil en la organización del sistema financiero, pues está encargado de desarrollar las funciones de monopolio de emisión, banquero del gobierno, banco de los bancos, supervisor del propio sistema financiero, ejecutor de la política monetaria, ejecutor de la política cambial y de las reservas internacionales.

3 Fortuna, E.: Mercado Financeiro: Produtos e Serviços, $16 .^{a}$ ed, Qualitymark, Rio de Janeiro, 2005, p. 16.

4 BRASIL: Constitución Federal de 1988. Disponible en http://www.planalto.gov.br/ ccivil_03/constituicao/constituicaocompilado.htm. Acceso en el 08 may. 2018.

5 Siıva, José A.: Curso de Direito Constitucional, 26 ed, Malheiros, São Paulo, 2006, p. 826. 
Verificada su funcionalidad, el Banco Central de Brasil asume la misión de «assegurar a estabilidade do poder de compra da moeda e um sistema financeiro sólido e eficiente. No exercício das suas diversas funções, o BCB, por sua atuação autônoma, pela qualidade dos seus produtos e serviços e pela competência dos seus servidores, é uma instituição essencial à estabilidade econômica e financeira, indispensável ao desenvolvimento sustentável e à melhor distribuição de renda no Brasil» 6 .

Indiferentemente de la responsabilidad por el arreglo de las situaciones que se despliegan en el orden económico, el Banco Central brasileño no puede alejarse de las cuestiones sociales y ambientales. Su ejercicio regulador y fiscalizador debe materializar un comprometimiento efectivo con los matices que orientan hacia el desarrollo sostenible, de modo que todas las operaciones no pueden, bajo cualquier hipótesis, poner en riesgo la integridad del hombre y del medio ambiente natural.

Causa de ello, queda muy clara la idea de que la relación del Banco Central de Brasil con la comunidad «caminha rumo à transparência e ao diálogo, no esteio do processo de redemocratização do país e também de uma mudança global em termos da relação do Estado com a sociedade. O Bacen possui responsabilidade social singular, relativamente a outras organizações, sejam públicas ou privadas» ${ }^{7}$.

Hoy por hoy, la actuación del Banco Central de Brasil está pautada en la observación de criterios socio ambientales para la emisión de normas reguladoras, inherentes al funcionamiento de las instituciones que integran el sistema financiero brasileño, y de la relación de estas con sus clientes. El Banco Central de Brasil posee responsabilidad socio ambiental integrada a la organización de su estructura y constante de las normas que edita.

No obstante, es inevitable destacar que el Banco Central de Brasil tiene una responsabilidad social y ambiental distinta de las otras instituciones que integran el sistema financiero brasileño y diferente de la responsabilidad de otros Bancos Centrales. Lima puntea que, «como órgão regulador e supervisor do sistema financeiro, o Bacen busca estabelecer padrões de funcionamento para as instituições financeiras,

6 Banco Central do Brasil: Funções do Banco Central do Brasil. Disponible en http:// www.bcb.gov.br/conteudo/home-ptbr/FAQs/FAQ\%2011-Fun\%C3\%A7\%C3\%B5es\%20 do\%20Banco\%20Central.pdf. Acceso en el 08 may. 2018.

7 SouzA LIMA, Sérgio A.: "Banco Central e Responsabilidade Social», Boletim Responsabilidade Social Ambiental do Sistema Financeiro, Brasília, BACEN, 2009, p. 1. 
sempre alinhados às melhores práticas nacionais e internacionais, que hoje são impregnadas de preocupações socioambientais. ${ }^{8}$

Asimismo, Souza subraya que el Banco Central de Brasil es el "agente da sociedade destinado à segurança do equilíbrio monetário da Nação, mediante o zelo da liquidez da economia, a garantia da formação de poupança e a estabilidade e aperfeiçoamento do Sistema Financeiro Nacional» ${ }^{9}$.

\section{Las cooperativas financieras en el contexto del sistema financiero brasileño}

El Cooperativismo de crédito, o Cooperativismo financiero, comprende una de las ramas del Cooperativismo, y tiene como peculiaridad «la prestación de servicios financieros a sus miembros, y de forma limitada, para personas externas al cuadro de asociados, siempre buscando optimizar el atendimiento de sus respectivas necesidades de crédito, ahorro y demás servicios» 10 .

A par de ello, las sociedades cooperativas financieras desarrollan programas de asistencia financiera y de prestación de servicios a sus cooperados. Su finalidad es la atención a la necesidad de crédito, ofreciéndole con una propuesta actitudinal, que la hace distinta de las demás instituciones financieras, sean públicas o privadas.

De acuerdo con esta realidad, y en atención a la disposición del artículo 192, de la Constitución Federal de Brasil, las cooperativas de crédito son entidades privadas que participan da estructura del sistema financiero brasileño, pues su objeto de actividad es prestar servicios de aspecto financiero, y de crédito.

Las cooperativas financieras son reconocidas como instituciones financieras que hacen parte del contexto estructural del Banco Central de Brasil, una vez que, además de ser personas jurídicas privadas, operan en la «accesoria la coleta, cosecha, intermediación o aplicación de recursos financieros propios o de terceros, en moneda corriente o extranjera, y la custodias de valor de propiedad o terceros» ${ }^{11}$.

8 Ibid., p. 1.

9 SouzA, Leonardo R.: Cooperativas de crédito: regulação do CMN e os valores cooperativos, Curitiba, Juruá, 2017, p. 75.

10 MiRANDA, José Eduardo de: «El sistema de crédito cooperativo brasileño y la identidade cooperativa: la necesidad de vigilancia permanente», Boletín de la Asociación Internacional de Derecho Cooperativo, Bilbao, Universidad de Deusto, 2015, p. 77.

11 Brasil: Lei 4.595, de 31 de dezembro de 1964. Disponible en el http://www.planalto.gov.br/CCivil_03/leis/L4595.htm». Acceso en 08 may 2018. 
Sin embargo, para evitar cualquier desvío de finalidad y de naturaleza de la cooperativa financiera, hay que llamarse "la atención al hecho de que en la medida que el artículo primero, de la Ley Complementar 130/2009, de las cooperativas financieras brasileñas, determina que las instituciones constituidas bajo la forma de cooperativas financieras deben someterse a la legislación específica del Sistema Financiero de Brasil». ${ }^{12}$ En este punto, es necesario decir que la Ley 130/2009 dispone sobre el sistema brasileño de cooperativismo financiero, «entendido como a estruturação sistémica do Cooperativismo de crédito em quatro tipos específicos de entidades: as cooperativas singulares de crédito, as cooperativas centrais de crédito, as confederações de cooperativsa de crédito e os bancos cooperativos» ${ }^{13}$.

De outra manera, Souza advierte que las cooperativas financieras «devem ser classificadas também a partir da sua atividade econômica básica, no caso, proporcionar através da mutualidade e da economia a prestação de serviços financeiros aos seus associados. Dessa forma, ao captar, aplicar e intermediar recursos financeiros de seus associados, as cooperativas de crédito são instituições financeiras e, por isso, estão sujeitas à aplicabilidade da Lei Federal 4.595/1964». ${ }^{14}$

\section{El objetivo de la Resolución 4.327/2014, del Banco Central de Brasil, y el sentido de la Política de Responsabilidad Socio Ambiental}

Hace mucho que el Banco Central de Brasil camina al encuentro de las acciones internacionales en materia de responsabilidad social y ambiental, procurando establecer una conducta sólida, y no solamente formal, en la búsqueda por el conocimiento de certificaciones y desarrollo de estudios sobre el tema. En este sentido, se puede decir que la Resolución 4.237, editada en el 25 de abril del 2014, surge para adecuar el ejercicio de las instituciones financieras brasileñas a las prácticas económicas sostenibles.

Es así que dicha resolución instituye las directrices que deben ser observadas para el desarrollo y ejecución de las políticas de responsabilidad socio ambiental, por parte de las instituciones financieras que hacen parte de la estructura del Sistema Financiero de Brasil.

12 MiRANDA, 2015, p. 78.

3 SOUZA, 2017, p. 85.

14 Ibid., p. 76. 
Por tanto, resuelta muy claro que el objetivo de la Resolución 4.327/2014, del Banco Central de Brasil, es promover la implantación sistémica de la gestión del análisis de los riesgos sociales y ambientales, haciéndoles elemento inherente a los negocios de las instituciones financieras.

A par de ello, es necesario decir que la proyección de unas políticas de responsabilidad social y ambiental corresponde al establecimiento de toda una dinámica de gestión de las instituciones financieras, desarrollada con el propósito de minimizar el riesgo social y ambiental de los negocios que puedan derivar de los negocios económicos, financieros y de crédito.

No se puede olvidar que los riesgos sociales y ambientales «que permeiam os projetos, têm potencial de perdas bastante alto em razão de atrasos e paralisações nas obras, de publicidade negativa, de ameaças de cassação de licenças e de gastos não previstos. Ao mesmo tempo, os danos à reputação de uma empresa podem superar consideravelmente os custos imediatos do projeto. Os riscos socioambientais devem ser identificados pelas instituições financeiras como um componente das diversas modalidades de risco a que estão expostas. ${ }^{15}$

Partiéndose del principio de que los daños socio ambientales están directamente relacionados con la exclusión social, la polución, los daños a la salud humana, la seguridad de las personas y los impactos por eventuales amenazas a la biodiversidad, las instituciones financieras, y por ello, las cooperativas, se muestran expuestas constantes a los riesgos de daños sociales y ambientales, a través de sus respectivos usuarios y clientes. La incapacidad de gerenciamiento de los riesgos sociales y ambientales puede afectar la vida de las instituciones financieras y la propia credibilidad del sistema financiero nacional.

Entonces, las políticas de responsabilidad socio ambiental deben ser desarrolladas en el seno de todas las instituciones financieras, y su conformación necesita observar los principios de la relevancia y de la proporcionalidad. A través del principio de la relevancia, las instituciones necesitan observar el grado de exposición del riesgo social y ambiental de las actividades y operaciones que desarrollan, sean propias o de terceros. El principio de la proporcionalidad, a su vez, establece que la institución debe observar la compatibilidad entre las acciones de responsabilidad social y ambiental con las actividades y servicios que ofrece.

15 AbBC Educacional: O que é a política de responsabilidade socioambiental para bancos? Disponible en http://www.abbc.org.br/cursos/artigo.asp?id=2. Acceso en 08 may 2018. 
La responsabilidad social y ambiental demuestra la humanización de las actividades financieras, pues, una vez que también el riesgo de las actividades económicas desarrolladas por los clientes y usuarios de las instituciones financieras son objeto de análisis, la idea es viabilizar la minimización de daños al medio natural y a las personas, disminuyendo, por supuesto, la afectación a la dignidad humana. Para ello, las políticas de responsabilidad socio ambiental precisan «estabelecer diretrizes sobre as ações estratégicas relacionadas à sua governança, inclusive para fins do gerenciamento do risco socioambiental» ${ }^{16}$.

\section{La Resolución 4.327/2014 en el escenario de las cooperativas financieras}

Por su condición de entidad parte del Sistema Financiero brasileño, a las cooperativas financieras no les resta otra alternativa que la adaptación de sus estatutos y regimientos a las exigencias de la Resolución 4.327/2014. Es decir, los términos de la resolución debe ser inseridos en el cuerpo normativo de la cooperativa, para que pueda ser materializado a lo largo del ejercicio de su negocio.

El plazo para el ajuste de los estatutos, y la actualización de sus regimientos, promoviendo la inserción de las políticas de responsabilidad social y ambiental agotó en el 31 de julio del 2015. Créese así, que las cooperativas financieras brasileñas cumplieron los términos del artículo 3. ${ }^{\circ}$, de Resolución 4.327/2014, del Banco Central de Brasil, formateando unas políticas de responsabilidad socio ambiental compatible con su porte, con la naturaleza de un negocio y con la complejidad de los productos y servicios ofrecidos.

Para ello, las cooperativas financieras necesitaron involucrar su capital humano, involucrando a los cooperados y empleados, para conformar una propuesta de gestión integrada, a través de la cual se pueda identificar:

- Una estructura de gobernanza exclusiva para las cuestiones de naturaleza social y ambiental;

— Las formas de gestión de los riesgos socio ambientales;

16 Banco Central do Brasil: Resolução 4.237/2014, de 24 de abril de 2014. Disponible en http://www.bcb.gov.br/pre/normativos/res/2014/pdf/res_4327_v1_O.pdf. Acceso en 08 may 2018. 
- La descripción de las actividades y prácticas que deben ser implementadas de acuerdo con los principios de la relevancia, de la proporcionalidad, sin desprecio de los principios de la razonabilidad y eficacia;

- Las técnicas de sensibilización de los cooperados, de los empleados, del os clientes y de la gente de la comunidad;

- Los mecanismos de capacitación de empleados y cooperados;

- La divulgación y las formas de actualización de las políticas de responsabilidad social y ambiental.

Las cooperativas financieras debieron nombrar un Director de Responsabilidad Social y Ambiental, destinándole cuantos empleados fuesen necesarios a la implementación de las respectivas políticas.

Además de ello, el artículo 6. ${ }^{\circ}$, de la Resolución 4.327/2014, del Banco Central de Brasil, las cooperativas financieras tuvieron que establecer un sistema de gestión de riesgos, encargado de desarrollar ${ }^{17}$ :

- «Sistemas, rutinas y procedimientos para - identificación, clasificación, evaluación y control del riesgo ambiental presente en las actividades y en las operaciones.»

— «El registro de datos referentes a las pérdidas decurrentes de los daños ambientales, por un periodo de cinco años, incluyendo valores, tipo, sitio y sector económico objeto de la operación.»

— «Evaluación previa de los potenciales impactos socio ambientales de nuevas modalidades de productos y servicios.»

— «Procedimientos para la adecuación de la gestión del riesgo socio ambiental a los cambios legales.»

De hecho, y a pesar de la gestión de los riesgos ambientales y sociales constar de las políticas de responsabilidad socio ambiental, su ejecución está vinculada a una unidad, o departamento, de gestión general de los riesgos de la cooperativa financiera.

Además, es conveniente tener en cuenta que las políticas de responsabilidad socio ambiental necesitan ser aprobada por el Consejo de Administración de la cooperativa financiera, para que se tenga asegurada la necesaria integración de la propuesta con todos los órganos y personas vinculadas a cooperativa.

17 Todo de acuerdo con el texto del artículo $6^{\circ}$, de la Resolución Resolución 4.327/2014, del Banco Central de Brasil. 


\section{La tenacidad de los principios cooperativos de la educación e información y de la preocupación por la comunidad en el proceso de ejecución de la Resolución 4.327/2014}

La Cúpula de las Naciones Unidas adoptó, en el mes de septiembre del 2015, la Agenda 2030 para el Desarrollo Sostenible, consistente en una Declaración de 17 Objetivos de Desarrollos Sostenible y 169 metas. Esta Agenda resuelta de los trabajos implementados en la Cúpula Mundial sobre Desarrollo Sostenible, del 2002, de la Cúpula de 2010, sobre os ODM, y de la Conferencia de las Naciones Unidas sobre Desarrollo Sostenible de 2011 , la Rio $+20^{18}$.

Los 17 objetivos, cuya implementación debe ser promovida a través de la cooperación de los países que firmaran la declaración, son ${ }^{19}$.

— «Fin de la pobreza: acabar con la pobreza en todas sus formas y en todos los sitios»;

— «Hambre cero: acabar con el hambre, alcanzar la seguridad alimentar y la mejoría de la nutrición y promover la agricultura sostenible»;

— «Salud y bienestar: asegurar una vida saludable y promover el bienestar para todos y para todas, en todas las edades»;

— «Educación de calidad: garantizar la educación inclusiva y equitativa de calidad, y promover oportunidades de aprendizaje a lo largo de la vida para todos y todas»;

- «lgualdad de género: alcanzar la igualdad de género y empoderar a todos las mujeres y chicas»;

— «Agua limpia y saneamiento: garantizar la disponibilidad y la gestión del agua y del saneamiento para todos»;

— «Energía asequible y no contaminante: asegurar el acceso confiable, sostenible, moderno y a precio accesible de energía para todos»;

— «Trabajo decente y crecimiento económico: promover el crecimiento económico sustentado, inclusivo y sostenible, empleo pleno y productivo y el trabajo decente para todos»;

— «Industria, innovación y tecnología: construir infraestructuras adaptables, promover la industrialización inclusiva e sostenible y fomentar la innovación»;

18 Cúpula das Nações Unidas sobre Desenvolvimento Sustentável: Transformar nosso mundo para as pessoas e o planeta. Disponible en «https://nacoesunidas.org/pos2015/ cupula/» Acceso en el 06 may. 2018.

19 Disponibles en http://www.undp.org/content/undp/es/home/sustainable-development-goals.html. 
— «Reducción de las desigualdades: reducir las desigualdades dentro de los países y entre ellos»;

— «Ciudades y comunidades sostenibles: tornar las ciudades y los asentamientos humanos inclusivos, seguros adaptables y sostenibles;

- Producción y consumo responsables: garantizar patrones de producción y consumo sostenibles»;

— «Acción por el clima: tomar medidas urgentes para combatir los cabios del clima y sus impactos»;

- «Vida submarina: conservación y uso de los océanos, de los mares y de los recursos marinos para el desarrollo sostenible»;

— «Vida de ecosistemas terrestres: proteger, recuperar y promover el uso sostenible de los ecosistemas terrestres, gestionar de forma sostenible las florestas, combatir la desertificación, detener y reverter la degradación de la tierra, y detener la perdida de la biodiversidad»;

— «Paz, justicia e instituciones sólidas: promover sociedades pacíficas e inclusivas para el desarrollo sostenible, proporcionar el acceso a la justicia para todos y construir instituciones eficaces, responsables e inclusivas en todos los niveles»;

- «Alianzas para lograr objetivos: fortalecer los medios de implementación y revitalizar los convenios globales para el desarrollo sostenible».

Mirándose hacia el contenido unificado de los 17 Objetivos de Desarrollo Sostenible, se puede comprender que la Organización de las Naciones Unidas quiere "garantizar los derechos humanos, acabar con la pobreza, luchar contra la desigualdad y la injusticia, alcanzar la igualdad de género y el empoderamiento de las mujeres y chicas, bien cómo enfrentar otros desafíos de nuestros tiempos» 20 .

De otra forma, es posible observar que los Objetivos de DesarroIlo Sostenible son «integrados e indivisibles, y mezclan, de forma equilibrada, las tres dimensiones del desarrollo sostenible: la económica, la social y la ambiental» ${ }^{21}$.

Una vez constatado el carácter integrativo e indivisible de los Objetivos de Desarrollo Sostenible, es imposible que se aplique uno de los

20 ONUBR. Roteiro para a Localização dos Objetivos de Desenvolvimento Sustentável: Implementação e Acompanhamento no nível subnacional. 2016. Disponible en https://nacoesunidas.org/wp-content/uploads/2017/06/Roteiro-para-a-Localizacao-dosODS.pdf. Acceso en 07 may. 2018.

21 Ibid.. 
objetivos en desprecio de otro, porque el suceso de cualquiera necesita la vigilancia permanente del conjunto.

Es de este modo que, al verificarse el propósito de la Resolución 4.327/2014, del Banco Central de Brasil, se debe rescatar la idea de que los principios cooperativos determinan las cualidades esenciales que hacen que las cooperativas sean diferentes a los otros tipos de empresa y que el movimiento cooperativo sea valioso. Por tanto, su importancia dogmática es evidente, aunque su transcendencia jurídica queda supeditada a los términos en que hayan sido incorporados en las respectivas legislaciones internas, lo que condiciona notablemente su posible eficacia como criterios correctores de las posibles impurezas del legislador correspondiente» ${ }^{22}$

Visto esto, resta muy claro que, indiferentemente de las normas reguladoras de las cooperativas financieras, las cuestiones sociales y ambientales están en su gen actitudinal, teniendo en cuenta que la finalidad del Cooperativismo es la emancipación del hombre, a través de su transformación económica, social, moral, actitudinal...

A par de esto, y conectándose los Objetivos de Desarrollo Sostenible con la esencia de los principios del Cooperativismo, no se puede rechazar la importancia que los principios cooperativos de la educación y de la preocupación por la comunidad tiente en el escenario global, para que el mundo encuentre el verdadero significado de desarrollo sostenible.

Partiéndose de la idea de que la sostenibilidad es un supuesto, o una condicionante de consciencia humana, los principios de la educación e información y de la preocupación por la comunidad son instrumentos que permiten a las cooperativas financieras cumplir con los términos de la Resolución 4.327/2014, del Banco Central de Brasil, mediante un diferencial práctico de intención y ejecución.

Ambos los principios, junto con los demás, son idénticos al carácter de los Objetivos de Desarrollo Sostenible, pues, además de integrados e indivisibles, también se funden bajo las dimensiones económica, social y ambiental.

A lo largo del ejercicio de su negocio, las cooperativas financieras precisan hacer valer el principio de la preocupación por la comunidad, aproximando el dialogo con el entorno donde está inserida, para que pueda constatar las respectivas demandas que surgen en el ámbito social, ambiental y económico.

22 GAdEA, Enrique; SACRISTÁN, Fernando y VASSEROt, Carlos Vargas: Régimen jurídico de la sociedad cooperativa del siglo XXI. Realidad actual y propuestas de reforma, Dykinson, S. L., Madrid, 2009, p. 38. 
Las cooperativas necesitan ir hacia donde se encuentran las personas, para que sepa lo que precisa, y establezcan las medidas adecuadas para que suplanten sus carencias, tomando todas las actitudes, y desarrollando lo que sea necesario para que cumpla con su responsabilidad social y ambiental.

En este sentido, y de acuerdo con el hilo conductor de los Objetivos de Desarrollo Sostenible, el medio por lo cual las cooperativas pueden destacarse en sus políticas de responsabilidad socio ambiental es a través de una adecuada aplicación del principio de la educación, utilizándole para llevar información sobre inclusión, sostenibilidad y actitud humana hacia el seno de la comunidad.

Las cooperativas financieras, a través de la cooperación preconizada por las Naciones Unidas, deben tomar a cargo la educación de las personas, para que logre una efectiva transformación moral del hombre. Es únicamente a través de la educación y de la información que los ideales de sostenibilidad se harán efectivos en el seno social. No se puede olvidar que la propia Organización de las Naciones Unidas orienta en el sentido de que "as ações de sensibilização devem ter como objetivo incentivar a participação dos cidadãos e das comunidades locais a fim de promover a apropriação da Agenda e o engajamento na busca pelo alcance dos ODS no nível local. Mas a sensibilização não se limita a comunicar a existência dos ODS. É também sobre empoderar os cidadãos a participar ativamente na concretização dos ODS no dia-a-dia» ${ }^{23}$.

Por esto, las cooperativas financieras tienen una gran ventaja sobre las demás instituciones que componen el sistema financiero brasileño, pues, solamente ellas tienen en su cultura, y en su genética negocial la tenacidad necesaria para tomar a su cargo la educación de los cooperadores, de sus empleados y de las personas en general, pues, su escuela es la encargada de sembrar la inteligencia de los niños, el Cooperativismo puede cultivar su alma24.

\section{A título de conclusión: las políticas de responsabilidad social y ambiental son una tarea de casa, de las cooperativas financieras}

Cuando uno habla del desarrollo de políticas de responsabilidad social y ambiental, en el ámbito del mercado financiero, piensa en el «conjunto de iniciativas implementadas pelos empresários, de forma

23 ONUBR, 2016.

24 MIRANDA, 2012, p. 48. 
vocacional, ou voluntária, para a materialização de ações que respondam suas preocupações de natureza ética, social e ambiental às suas interações com clientes, colaboradores, fornecedores, concorrentes, acionistas, governos e comunidades, e confiram solidez ao desenvolvimento de empreendimentos efetivamente sustentáveis» ${ }^{25}$.

Mismo en el escenario de las instituciones financieras, la responsabilidad social y ambiental puede ser traducida «como um princípio ético, aplicado à realidade através de uma gestão que leva em consideração as necessidades e opiniões dos diferentes stakeholders, isto é, dos públicos envolvidos ou impactados pelo negócio das empresas: clientes, funcionários, acionistas, comunidades, meio ambiente, fornecedores, governo e outros» 26 .

Hablase, pues, de un principio ético, porque la inquietud por las cuestiones ambientales y sociales pone el hombre en el centro efectivo de toda la preocupación, de modo que todas las acciones desarrolladas en favor del medio ambiente y de la sociedad alcanzan la persona humana como beneficiaria. Este hecho, por cierto, aproxima la máxima de la responsabilidad socio ambiental al sistema cooperativo.

Es imposible olvidarse que, desde sus orígenes más remotas, el Cooperativismo surgió para aplacar las necesidades humanas, haciendo con que las gentes se aproximasen una de las otras para obrar en conjunto, incluso en el sentido de generar protección colectiva. «El Cooperativismo recorrió la historia de manos dadas con el hombre como una corriente que permitió que las gentes se aproximaran bajo valores y principios comunes, para eliminar todas las formas autoritarias de poder, y para permitir que el propio hombre encontrara los medios necesarios a su completo desarrollo en el ámbito material, económico, social, personal y espiritual» 27 .

Fue a través de la creación de la sociedad cooperativa que el Cooperativismo enseñó al «mundo y a los hombres la plena posibilidad de existencia de una empresa que suplante las características egoístas y

25 MiRANDA, José Eduardo de: «Do livre exercício da atividade empresarial à responsabilidade social como prerrogativa ético-moral da ordem econômica: a axiologia da cooperação como pressuposto de desenvolvimento sustentável», Ordem econômica constitucional: compreensão e comparativo da ordem econômica na constituição de 1988 com outros sistemas jurídicos, Curitiba, Juruá, 2015, p. 286.

26 BSD: Responsabilidade social empresarial.

Disponible en http://www.inmetro.gov.br/multiplicadores/respSocial.pdf. Acceso en 07 may. 2018.

27 MIRANDA, 2012, p. 16. 
primordiales de las entidades capitalistas, y se consolide bajo un perfil participativo, solidario, y de ayuda mutua» 28 .

Por ello que la Resolución 4.327/2014, del Banco Central de Brasil, no puede generar cualquier impacto en el orden de las cooperativas financieras brasileñas, teniendo en cuenta que su constitución y desarroIlo, a pesar de reglamentada por el Sistema Financiero de Brasil, está subrogada a adhesión estatutaria de los valores y principios del Cooperativismo.

Es verdad que las cooperativas financieras en Brasil son reconocidas como instituciones financieras. Se encargan de la prestación de servicios financieros, económicos, y otros similares, a sus miembros y clientes. A pesar de Brasil tener una Ley específica que orienta la constitución y el desarrollo de las cooperativas financieras, la norma reguladora y fiscalizadora de su ejercicio negocial siempre vendrá de los órganos del Sistema Financiera, haciendo sumisa de las Resoluciones del Banco Central de Brasil.

No obstante, la diferencia entre la cooperativa financiera y las demás instituciones que componen el sistema financiero brasileño es justamente su marco de valores y principios, todos determinantes de conductas y actitudes que sitúan la persona humana más arriba del valor del capital y del interés económico.

Se quiere decir, con esto, que el desarrollo de unas políticas de responsabilidad social y ambiental por las cooperativas financieras no puede representar una promoción sencillamente formal, de aspecto obligatorio, pues la esencia de la cooperatividad presupone que el sistema cooperativo existe para la promoción del bien social y del bienestar del hombre.

Los gestores de las cooperativas financieras tienen que percibir que el cumplimento de las directrices de la Resolución 4.327/2014, del Banco Central de Brasil, es nada más que poner en práctica la esencia del espíritu cooperativo, emergente de la comprensión de los valores y de los principios del Cooperativismo, determinantes de la ética cooperativa, que orienta a las cooperativas de todas las ramas actuaren siempre a partir de una perspectiva de sustentabilidad. Esto, lograran haciendo suyos los principios de la educación e información, y preocupación por la comunidad.

Más allá del análisis de riesgo de sus usuarios y clientes, las cooperativas financieras, en conjunto con las «associações e redes locais e re-

28 Miranda, José Eduardo de: Filosofía cooperativa: análisis del proceso de conformación del cooperativismo, Juruá, Curitiba, 2017, p. 15. 
gionais de governo devem realizar campanhas de sensibilização para mobilizar seus membros a compreender suas funções para o alcance dos ODS. Elas devem procurar aumentar o conhecimento e o senso de propriedade em relação aos ODS por todos os governos subnacionais, independentemente de seu tamanho ou nível de recursos, com o apoio dos governos nacionais e organizações internacionais» ${ }^{29}$.

La Resolución 4.327/2014, del Banco Central de Brasil, se muestra importante para recordar a los cooperativistas que las cuestiones de orden ambiental y social independen de una norma reguladora. Si las cuestiones sociales, y el medio equilibrado son indispensables para el bien de las personas, la responsabilidad socio ambiental está en los genes de las cooperativas financieras, porque el bienestar del hombre es la esencia en si misma del espirito de la cooperación-cooperativa.

\section{Referencias}

AbBC EDUCACIONAL: O que é a política de responsabilidade socioambiental para bancos? Disponible en http://www.abbc.org.br/cursos/artigo.asp?id=2. Acceso en 08 may 2018.

Assaf Neto, A.: Mercado financeiro, 4. ${ }^{a}$ ed, Atlas, São Paulo, 2001.

Banco Central do Brasil: Funções do Banco Central do Brasil. Disponible en http://www.bcb.gov.br/conteudo/home-ptbr/FAQs/FAQ\%2011Fun\%C3\%A7\%C3\%B5es\%20do\%20Banco\%20Central.pdf. Acceso en el 08 may. 2018.

Banco Central do Brasil. Resolução 4.327/2014, de 24 de abril de 2014. Disponible en http://www.bcb.gov.br/pre/normativos/res/2014/pdf/res_4327_ v1_O.pdf. Acceso en 08 may 2018.

BrASIL: Constitución Federal de 1988. Disponible en http://www.planalto.gov. br/ccivil_03/constituicao/constituicaocompilado.htm. Acceso en el 08 may. 2018.

BrASIL: Lei 4.595, de 31 de dezembro de 1964. Disponible en http://www.planalto.gov.br/CCivil_03/leis/L4595.htm. Acceso en el 08 may. 2018.

CÚPULA DAS NAÇõeS UNIDAS SOBRE DESENVOLVIMENTO SUSTENTÁVEL: Transformar nosSO mundo para as pessoas e o planeta. Disponible en https://nacoesunidas. org/pos2015/cupula/. Acceso en el 06 may. 2018.

BSD: Responsabilidade social empresarial. Disponible en http://www.inmetro. gov.br/multiplicadores/respSocial.pdf. Acceso en el 07 may. 2018.

SouzA LIMA, Sérgio A.: «Banco Central e Responsabilidade Social», Boletim Responsabilidade Social Ambiental do Sistema Financeiro, Brasília, BACEN, 2009.

29 ONUBR, 2016. 
Etgeto, Anderson Augusto y otros: "Os princípios do cooperativismo e as cooperativas de crédito no Brasil», Maringa Management: Revista de Ciências Empresariais, v. 2, n. 1, p. 7-19, jan. /jun. 2005. Disponible en http:// www.maringamanagement.com.br/novo/index.php/ojs/\%20article/\%20 viewFile/30/15. Acceso en el 08 may. 2018.

ForTunA, E.: Mercado Financeiro: Produtos e Serviços, $16 .^{a}$ ed, Qualitymark, Rio de Janeiro, 2005.

GadeA, Enrique; SACRISTÁN, Fernando y VASSEROT, Carlos Vargas: Régimen jurídico de la sociedad cooperativa del siglo XXI. Realidad actual y propuestas de reforma, Dykinson, S. L., Madrid, 2009.

MIRANDA, José Eduardo de: "El sistema de crédito cooperativo brasileño y la identidad cooperativa: la necesidad de vigilancia permanente», Boletín de la Asociación Internacional de Derecho Cooperativo, Bilbao, Universidad de Deusto, 2015.

MIRANDA, José Eduardo de: «Do livre exercício da atividade empresarial à responsabilidade social como prerrogativa ético-moral da ordem econômica: a axiologia da cooperação como pressuposto de desenvolvimento sustentável», Ordem econômica constitucional: compreensão e comparativo da ordem econômica na constituição de 1988 com outros sistemas jurídicos, Curitiba, Juruá, 2015.

MIRANDA, José Eduardo de: De la crisis de identidad al rescate de la génesis del cooperativismo, Dykinson, Madrid, 2012.

MIRANDA, José Eduardo de: Filosofía cooperativa: análisis del proceso de conformación del cooperativismo, Juruá, Curitiba, 2017.

ONUBR: Roteiro para a Localização dos Objetivos de Desenvolvimento Sustentável: Implementação e Acompanhamento no nível subnacional. Disponible en https://nacoesunidas.org/wp-content/uploads/2017/06/Roteiro-para-aLocalizacao-dos-ODS.pdf. Acceso en 07 may. 2018.

Silva, José A.: Curso de Direito Constitucional, 26 ed, Malheiros, São Paulo, 2006.

SouzA, Leonardo R.: Cooperativas de crédito: regulação do CMN e os valores cooperativos, Curitiba, Juruá, 2017. 